\title{
Resveratrol affects the migration and apoptosis of monocytes by blocking HMGB1/NF-кB pathway
}

\author{
Yuwei Zhang, Qiaoliang Dong, Chan Liu, Yingfei Zhu, Xueli Qin, Zihan Qi, Xi Zhang, Hongmei Guo, \\ Weixiang Li, Meng Liu, Lin Gan, Hong Liu \\ Department of International Medical, Second Xiangya Hospital, Central South University, Changsha, China \\ Contributions: (I) Conception and design: H Liu, Y Zhang; (II) Administrative support: M Liu, L Gan; (III) Provision of study materials or patients: Q \\ Dong, C Liu; (IV) Collection and assembly of data: Y Zhang, Y Zhu, X Qin, Z Qi, X Zhang; (V) Data analysis and interpretation: Y Zhang, H Guo, \\ W Li; (VI) Manuscript writing: All authors; (VII) Final approval of manuscript: All authors. \\ Correspondence to: Hong Liu. Department of International Medical, Second Xiangya Hospital, Central South University, Changsha, China. Email: \\ Katherinehong@csu.edu.cn.
}

Background: Chronic inflammation is now recognized as a causal factor of aging. Resveratrol is a non-
flavonoid compound that widely exists in plant species, exerting anti-inflammatory effects in vitro and
in animal models. The chemotaxis of inflammatory cells and secretion of cytokines are key characters in
inflammation response.

Methods: The effects of lipopolysaccharide (LPS) and high mobility group box-1 (HMGB1) chromosomal on the migration, inflammatory response, and apoptosis of monocytes were detected. THP-1 cells were used to study the effects of resveratrol treatment on LPS- and HMGB-induced monocytes. We aimed to investigate the effect of Resveratrol on monocyte migration and the expression of a special cytokine named HMGB1 in THP-1 cells.

Results: Resveratrol obviously inhibited THP-1 migration induced by LPS. LPS increased the expression of HMGB1 and its release in THP-1 cells, which were both decreased by resveratrol. Resveratrol inhibited

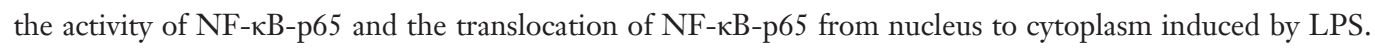
In addition, Resveratrol increased LPS and HMGB1-inhibited monocyte apoptosis. Resveratrol inhibited the LPS-induced HMGB1 secretion and its activation through NF- $\kappa$ B pathway. The THP-1 migration induced by LPS was inhibited by resveratrol.

Conclusions: Resveratrol may inhibit monocyte migration and induce apoptosis by blocking downstream HMGB1/NF-кB/MCP-1 signaling pathways, thereby reducing systemic inflammation.

Keywords: Resveratrol; high mobility group box-1 (HMGB1); lipopolysaccharide (LPS); monocyte; aging

Submitted Mar 22, 2021. Accepted for publication Jul 16, 2021.

doi: $10.21037 /$ tcr-21-517

View this article at: https://dx.doi.org/10.21037/tcr-21-517

\section{Introduction}

Inflammation is the essential pathological change in aging (1-3). Monocyte migration and proinflammatory secretion are important steps in inflammation response $(4,5)$. Among the cytokines participating in vascular inflammatory response, high mobility group box-1 (HMGB1) is special, because it can be released by necrotic cells or activated macrophages/monocytes in a delayed fashion (6-8).

Resveratrol is a non-flavonoid compound that widely exists in plant species, such as grapes and Polygonum cuspidatum, which is a Chinese traditional herb (9). Resveratrol attracted more interest in the past decade, because it is a biologically active polyphenol that exerts beneficial action on some most prevalent illnesses including cardiovascular diseases and cancer (10-13). It is postulated to be a promising agent to prevent vascular aging and extend lifespan (14). The therapeutic role of Resveratrol is related to its diversified properties, such as anti-inflammation, anti- 
proliferation, and anti-oxidative stress $(15,16)$. Even though some molecular mechanisms mediating the beneficial effects of Resveratrol have been identified, more targets of Resveratrol need to be investigated.

The anti-inflammatory property is critical for the pharmacological character of Resveratrol $(17,18)$. Resveratrol could inhibit the nuclear factor- $\kappa \mathrm{B}$ $(\mathrm{NF}-\kappa \mathrm{B})(10)$ activation and decrease the release of intercellular adhesion molecular-1 (ICAM-1), interleukin-6 (IL-6), and tumor necrosis factor $\alpha$ (TNF $\alpha$ ) induced by different stimuli (19). Reports on the effect of Resveratrol on HMGB1 or monocyte migration are rare.

THP-1 cells were used as the cell model. The effects of lipopolysaccharide (LPS)and HMGB1 on the migration, inflammatory response, and apoptosis of monocytes were detected by RT-qPCR, Transwell assay, and TUNEL assays. In addition, THP-1 cells were used to study the effects of resveratrol treatment on LPS- and HMGBinduced monocytes. Finally, we investigated the molecular mechanism underlying the effect of resveratrol treatment on monocytes through the interaction of HMGB1 with downstream signaling pathways.

We present the following article in accordance with the MDAR reporting checklist (available at https://dx.doi. org/10.21037/tcr-21-517).

\section{Methods}

\section{Cell culture}

THP-1 cells (RRID: CVCL_0006, purchased from Shanghai Institutes for Biological Science, Chinese Academy Science, China) were grown in RPMI 1640 medium supplemented with $10 \%$ fetal bovine serum at $37{ }^{\circ} \mathrm{C}$ in a $5 \% \mathrm{CO}_{2}$ atmosphere to a density of $1 \times 10^{6}$ cells $/ \mathrm{mL}$. The cells were randomly assigned to the following groups: negative control; LPS-treated group $(5 \mu \mathrm{g} / \mathrm{mL}$ ) (Sigma-Aldrich, USA); HMGB1-treated group $(1 \mu \mathrm{g} / \mathrm{mL})$ (Sigma-Aldrich, USA); and Resveratrol group $(20 \mu M)$ (Sigma-Aldrich, USA). All groups were collected for QRT-PCR and migration assay.

\section{Migration assay}

Transwell migration assays were performed with culture supernatant from different groups in the lower chamber and $2 \mathrm{ml}$ of THP- $1\left(5 \times 10^{4} / \mathrm{mL}\right)$ in the upper chamber in a 6 -well plate with $8-\mu M$ pore-size membrane (Corning,
USA) for $24 \mathrm{~h}$ at $37^{\circ} \mathrm{C}$. Cells that migrated into the lower chamber were collected and fixed with $95 \%$ alcohol. After hematoxylin-eosin staining, THP-1 cells in five 40x fields of view were counted under the inverted microscope. Migration experiments were repeated thrice.

\section{Real-time reverse transcription-polymerase chain reaction (RT-PCR)}

Total RNA was extracted and cDNA was synthesized with RevertAid H Minus First Strand cDNA Synthesis Kit (Fermentas, Canada) according to manufacturer's instructions. Stratagene MX3000 was used to analyze mRNA expression of HMGB1. The housekeeping gene GAPDH was used for internal normalization. HMGB1, sense: 5'-AAGTGAGAGCCGGACGGGCA-3', antisense: 5'-GGGCCTTGTCCGCTTTTGCCA-3'. Bcl-2, sense: 5'-ATGCCTTTGTGGAACTATATGGC-3', antisense: 5'-GGTATGCACCCAGAGTGATGC-3'. Bax, sense: 5'-TGAAGACAGGGGCCTTTTTG-3', antisense: 5'-AATTCGCCGGAGACACTCG-3'. TNF- $\alpha$, sense: 5'-CCTGTGAGGAGGACGAACA-3', antisense: 5', antisense: 5'-TTGAGCCAGAAGAGGTTGAG-3'. MCP-1, sense: 5'-CAGCCAGATGCAATCAATGCC-3', antisense: 5'-TGGAATCCTGAACCCACTTCT-3'. GAPDH, sense: 5'-CAATGACCCCTTCATTGACC-3', antisense: 5'- GACAAGCTTCCCGTTCTCAG-3' were designed by ProMab Biotechnologies Inc. Samples were run in triplicate. The efficiency of PCR was determined using dilution series of a standard vascular sample. Fidelity of the PCR reaction was determined by melting temperature analysis and visualization of product on a $2 \%$ agarose gel. Results are presented as relative quantification using the $2^{-\Delta \Delta C \mathrm{t}}$ method.

\section{Western blot}

Total protein and nuclear protein were extracted separately according to kit instruction (ProMab, USA). Protein concentration was measured by a Bradford Protein Assay kit (Beyotime Institute of Technology, China). Western blot was performed using the polyclonal rabbit antibody for NF-кB-p65 (1:400, $4{ }^{\circ} \mathrm{C}$ overnight; Abcam-ab16502, USA). Goat anti-rabbit IgG/HRP (1:40,000; ProMab-2005079, USA) was used as secondary antibody for NF-кB-p65 and Histone H2. Goat anti-mouse IgG/HRP (1:50,000; ProMab-2005080, USA) was used as secondary antibody for GAPDH. Histone H2 protein was used as an internal 
control for NF- $\mathrm{kB}-\mathrm{p} 65$. GADPH was used as an internal control for HMGB1. Gels were analyzed with Gel-Pro Analyzer Version 4.0. Protein expression was measured as the ratio of IOD with HMGB1/GADPH or NF-kB-p65/ Histone $\mathrm{H} 2$.

\section{Electrophoretic mobility shift assay (EMSA)}

Nuclear extracts were prepared in cells from negative control, LPS-stimulated, and $0.05 \mathrm{mM}$ Resveratrol groups. Binding reactions were conducted as described by the manufacturer (EMSA Kit from Pierce Biotechnology, USA). The sequence of the oligonucleotide was 5'-AGTTGAGGGGACTTTCCCAGGC-3' (synthesized at Beyotime Institute of Technology, China). The oligonucleotide was labeled with Biotin-N4-CTP. Labelled probe without incubation with the nuclear extract was used as the negative control, and Hela Nuclear Extracts (Merck, Germany) were used as the positive control. The IOD of NF- $\kappa$ B-p65 DNA-protein band was analyzed with Gel-Pro software 4.0.

\section{Immunofluorescence}

Cells from negative, LPS-stimulated, and $0.05 \mathrm{mM}$ Resveratrol groups were examined for immunofluorescence. Rabbit polyclonal antibody against human HMGB1 antigen $(50 \mu \mathrm{L}, 1: 200$; Abcam) and rabbit anti-goat $\operatorname{IgG}(50 \mu \mathrm{L}$, 1; 200; Alexa Fluor) were used. Immuno-labeled sections were treated with DAPI (4',6-diamidino-2-phenylindole) and examined under a fluorescent microscope, Images were acquired using AxioVision digital imaging system.

\section{CCK- 8 was used to detect cell proliferation}

After the cells reached the logarithmic growth stage, they were digested into a cell suspension. Cell suspension $\left(1.0 \times 10^{5} / \mathrm{mL}\right)$ was inoculated in a 96 -well plate at $100 \mathrm{\mu L} /$ well. The culture plate was placed in an incubator at $37^{\circ} \mathrm{C}$ and $5 \% \mathrm{CO}_{2}$ for $24 \mathrm{~h}$. The old culture medium was removed from each hole. After treatment, the cell culture medium in each well was discarded. CCK-8 and DMEM culture solutions at 10:100 were added under suitable dark conditions. Culture solutions at $100 \mu \mathrm{L}$ per well was placed in an incubator for $30 \mathrm{~min}$. The prepared culture plate was placed in an enzyme-linked immunodetector, and its absorbance (A) was detected at A wavelength of $450 \mathrm{~nm}$.

\section{TUNEL assay to detect cell apoptosis}

DNase I reaction solution was added to each group. Incubation was performed at $37{ }^{\circ} \mathrm{C}$ for $30 \mathrm{~min}$ and washed thrice with PBS. The TdT enzyme reaction solution was dripped onto the sample area. Incubation was performed in a $37^{\circ} \mathrm{C}$ wet box for $60 \mathrm{~min}$ (away from light) and washed thrice with PBS. Streptavidin-fluorescein marker liquid was dripped onto each sample. Each sample was placed in a warm box, reacted at $37^{\circ} \mathrm{C}$ for $30 \mathrm{~min}$ in the dark, and washed thrice with PBS. Finally, the nucleus was stained again with DAPI staining solution. The reaction took $10 \mathrm{~min}$ at room temperature and washed with PBS. An appropriate amount of sealing tablet was added, after which fluorescence microscope observation and photography (Nikon, Japan) were performed.

\section{Statistical analysis}

Standard software (SPSS 13.0 for Windows) was used for statistical analysis. Measurement data were expressed as mean \pm standard deviation (SD). Gaussian distribution test was conducted. One-way analysis of variance (ANOVA) was used to test the differences among the groups. Fisher's Least Significant Difference (LSD) method was used for post-hoc test to control for multiple testing. $\mathrm{P}<0.05$ was considered statistically significant.

\section{Ethical Statement}

The study was conducted in accordance with the Declaration of Helsinki (as revised in 2013).

\section{Results}

LPS induces THP-1 cells to release inflammatory factors; in addition, HMGB1 and NF- $\mathrm{BB}$ are upregulated in LPSinduced inflammatory response

To investigate the promoting effect of LPS on inflammatory factors, we first examined the changes in the expression levels of inflammatory factors after the LPS treatment of THP-1 cells. The experimental results showed that LPS could up-regulate the expression levels of inflammatory factors IL-6, TNF $\alpha$, and IL-1 $\beta$ (Figure $1 A-1 C$ ). The expression of MCP-1 was detected. QRT-PCR results showed that compared with the control group, the expression of MCP-1 was up-regulated after 
A

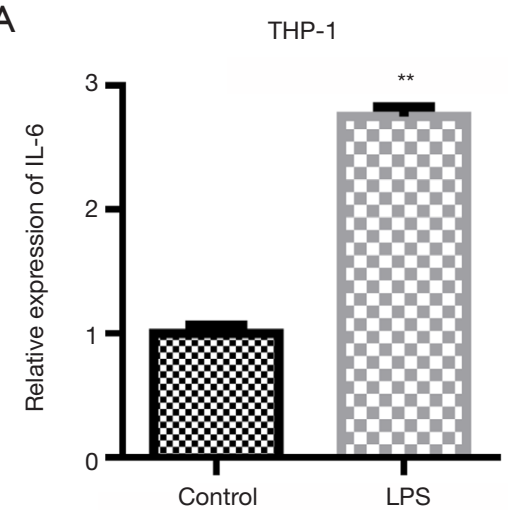

C

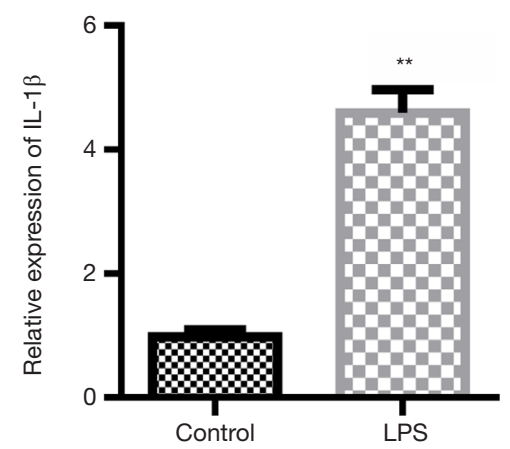

B

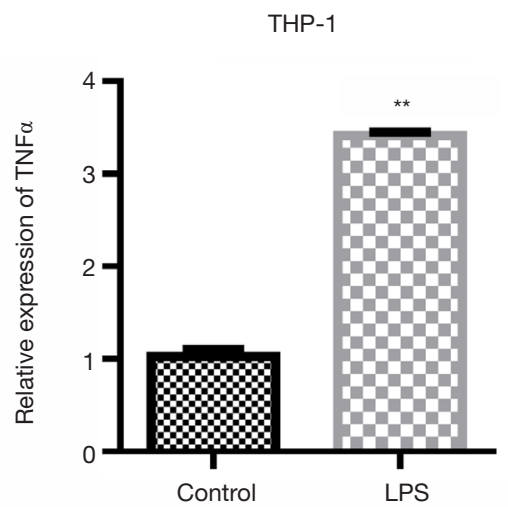

D

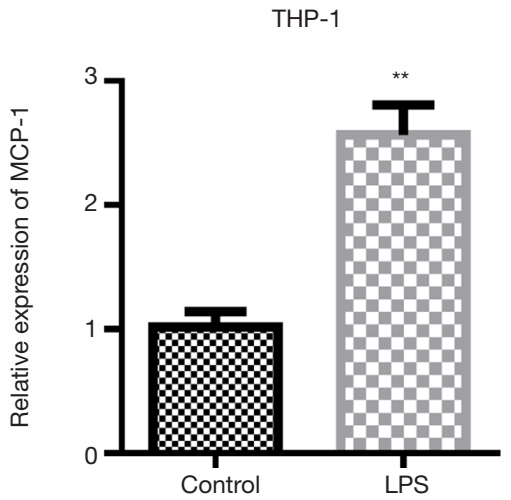

Figure 1 LPS induces THP-1 cells to release inflammatory factors. (A) Detection of IL-6 expression in cells; (B) detection of TNF $\alpha$ expression in cells; (C) detection of IL-1 $\beta$ expression in cells; (D) detection of MCP-1 expression in cells. Each bar represents the mean \pm $\mathrm{SD}$ for triplicate measurements. ${ }^{* *}, \mathrm{P}<0.01$.

LPS stimulation (Figure 1D).

QRT-PCR test showed that the expressions of HMGB1 and NF- $\kappa \mathrm{B}$ in cells were different among the groups $(\mathrm{P}<0.01)$. LPS stimulation obviously increased the levels of HMGB1 and NF- $\kappa \mathrm{B}$ in the supernatant when compared with the level in the control group (Figure 2A,2B). Transwell migration assays showed that supernatant from cells treated with $5 \mu \mathrm{g} / \mathrm{mL}$ LPS markedly increased the number of THP-1 cells migrating to the lower chamber (Figure 2C, $\mathrm{P}<0.05)$.

\section{Resveratrol treatment inhibits LPS-induced monocyte migration and inflammation}

QRT-PCR showed that the expression of IL-6, TNFa and IL-1 $\beta$ were different among the groups (ANOVA: both $\mathrm{P}<0.01)$. LPS stimulation increased the levels of IL-6, TNF $\alpha$, and IL- $1 \beta$ when compared with the level in the control group. Resveratrol at concentration of $20 \mu \mathrm{M}$ decreased the levels of IL-6, TNF $\alpha$, and IL-1 $\beta$ (Figure 3A-3C). The change of MCP-1 was similar to that of inflammatory factors (Figure $3 D$ ). Transwell migration assays showed that LPS increased the migration of THP1 cells. Resveratrol group showed a decreased number of THP-1 cells when compared with the LPS-stimulated group (Figure 3E). We further investigated the HMGB1 expression among the control, LPS-stimulated, and Resveratrol groups. HMGB1 expression was elevated by LPS stimulation when compared with the control group $(\mathrm{P}<0.001)$, whereas its level was inhibited by resveratrol intervention (Figure $3 F, \mathrm{P}<0.001$ ). To understand the role of NF- $\mathrm{NB}$ in Resveratrol intervention, we analyzed the $\mathrm{NF}-\kappa \mathrm{B}$ protein expression and its activity. Western blot analysis showed that LPS stimulation greatly increased the NF-кB-p65 protein level (Figure $3 G, \mathrm{P}<0.001$ ), but this increase was blocked by resveratrol intervention $(\mathrm{P}<0.001)$. 
A

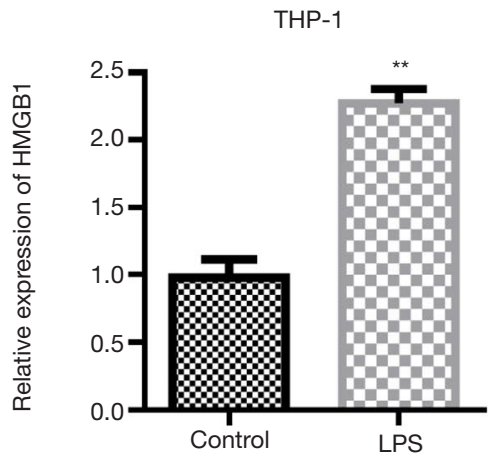

C

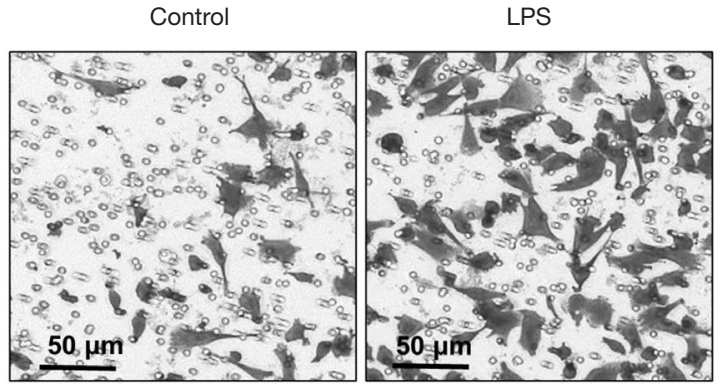

B
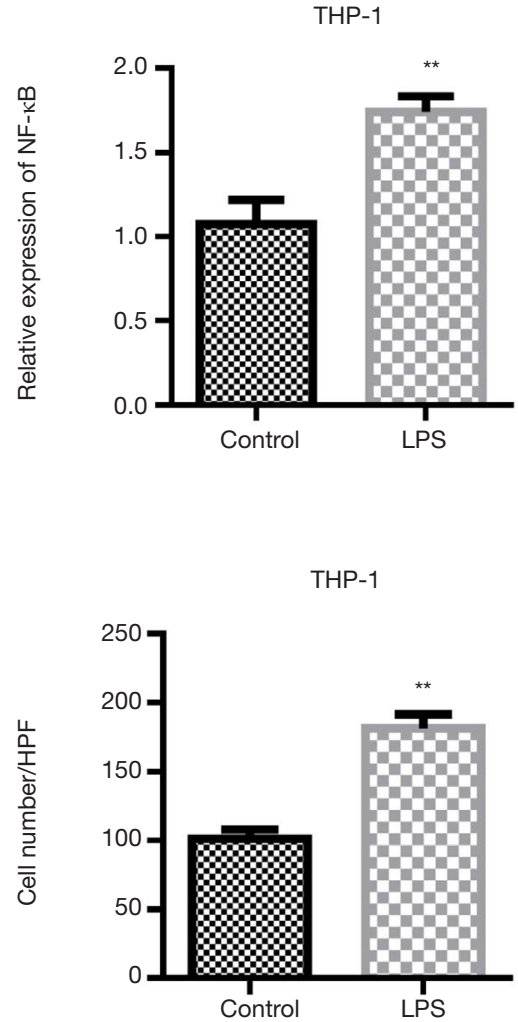

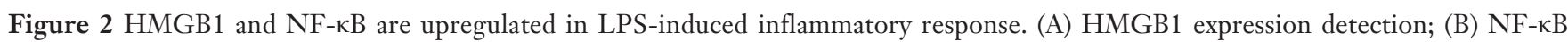
expression detection; $(\mathrm{C})$ transwell detects changes in cell migration ability. Each bar represents the mean \pm SD for triplicate measurements. **, $\mathrm{P}<0.01$.

Electrophoretic mobility shift assay (EMSA) was applied to determine the activity of NF- $\mathrm{kB}-\mathrm{p} 65$. After incubating with LPS for $24 \mathrm{~h}$, the DNA binding activity of NF- $\mathrm{kB}-\mathrm{p} 65$ was significantly increased, whereas preconditioning with Resveratrol for $2 \mathrm{~h}$ greatly inhibited the stimulating effect of LPS on NF-kB-p65 activity (Figure 3H).

\section{Resveratrol treatment inhibits the migration and inflammation of monocytes induced by HMGB1}

We further examined the role of HMGB1. Compared with the control group, HMGB1 stimulation increased the levels of IL-6, TNF $\alpha$, and IL-1 $\beta$. However, Resveratrol decreased the levels of IL-6, TNF $\alpha$, and IL- $1 \beta$ (Figure $4 A-4 C$ ). The change of MCP-1 was similar with those of the inflammatory factors (Figure 4D). Transwell migration assays showed that HMGB1 increased the migration of THP-1 cells. When compared with the LPSstimulated group, Resveratrol-treated group showed a decrease in the number of THP-1 cells (Figure 4E). In addition, LPS stimulation greatly increased the expression of NF- $\mathrm{KB}$, but this increase was blocked by resveratrol intervention (Figure 4F).

\section{Resveratrol treatment increases monocyte apoptosis and reverses the anti-apoptotic effect induced by LPS}

THP-1 cells are stimulated by STS and LPS. The apoptosis rate was low in the control group. STS significantly induced apoptosis. LPS stimulation inhibited cell apoptosis. However, Resveratrol treatment improved the apoptosis rate (Figure $5 \mathrm{~A}$ ). In addition, changes in apoptosis-related protein expression were investigated. QRT-PCR results showed that compared with the control group, apoptosisrelated proteins Bax and Cyt-C were significantly increased in the STS treatment group. LPS treatment reduced the expression of Bax and Cyt-C. However, resveratrol upregulated the expression of Bax and Cyt-C (Figure 5B,5C). The variation trend of Bcl-2 expression was contrary to that of Bax (Figure 5D). The cell proliferation experiment results 
A

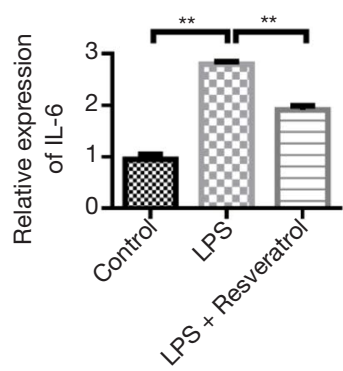

B

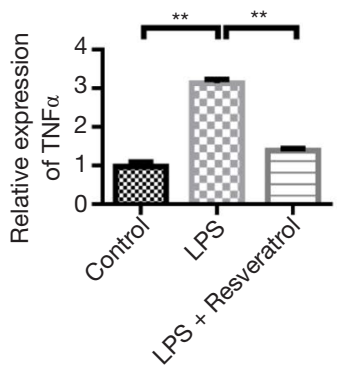

C

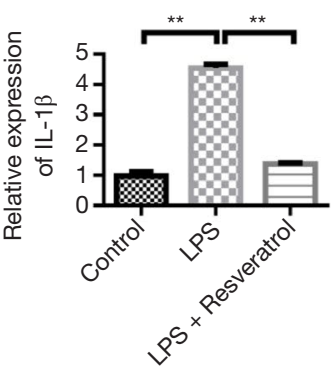

D

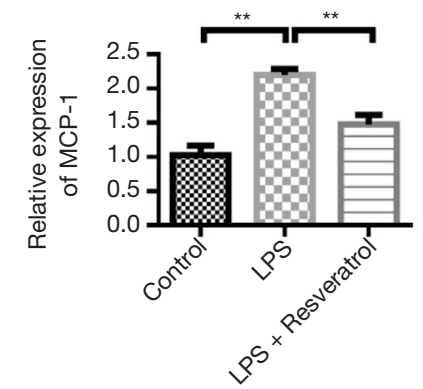

E

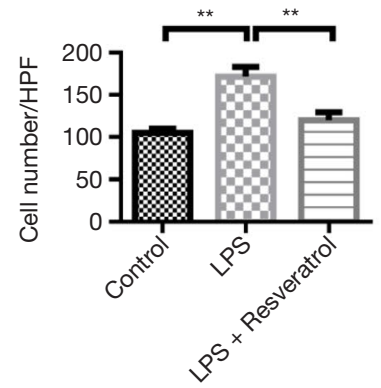

$\mathrm{F}$
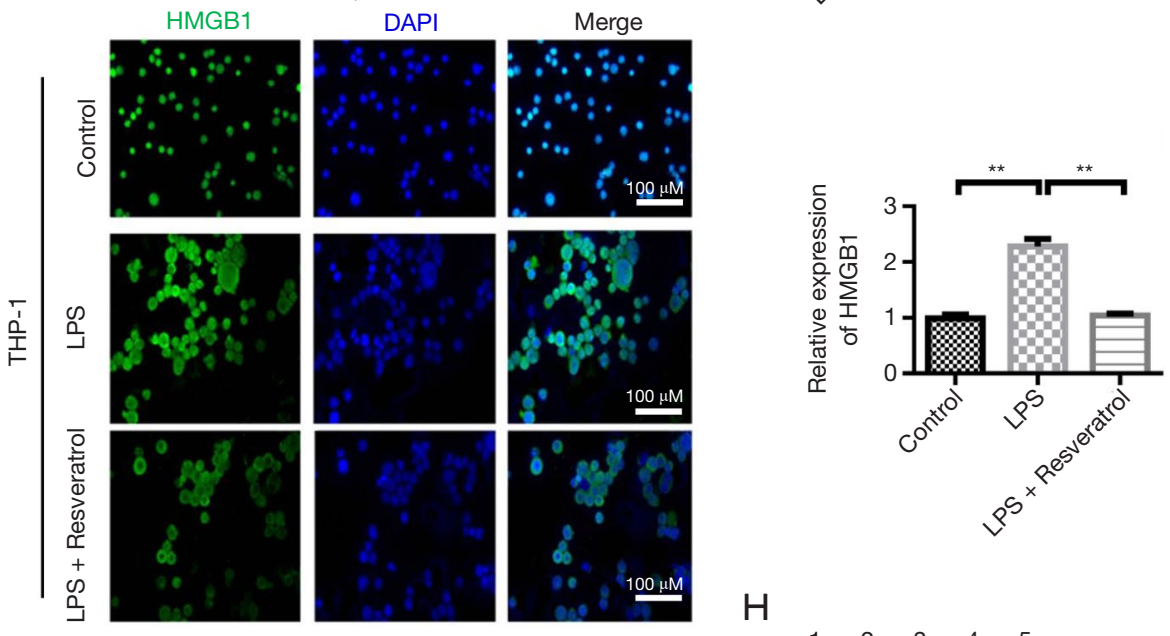

$\mathrm{H}$
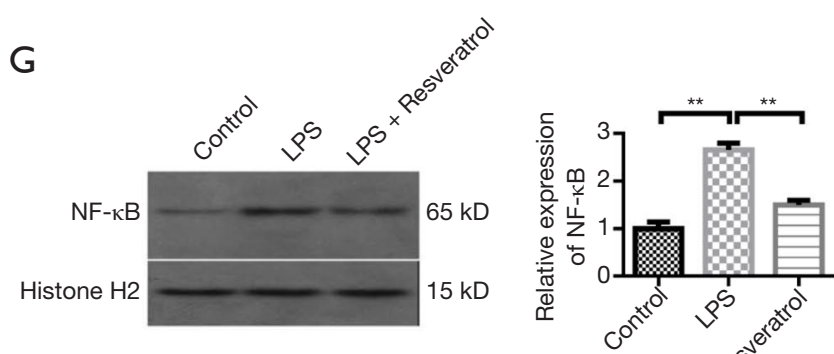

$\begin{array}{lllll}1 & 2 & 3 & 4 & 5\end{array}$

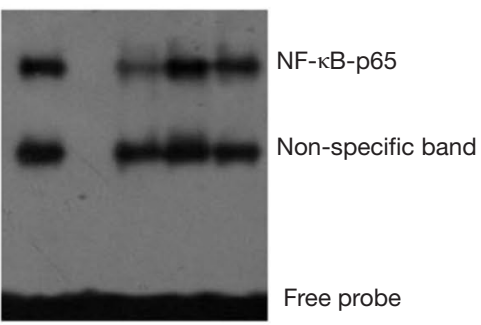

1: Positive control (Hela control Nuclear Extract)

2: Negative control (probe only)

3: Blank control

4: LPS $(5 \mu \mathrm{g} / \mathrm{mL})$ stimulated group

5: Resveratrol $(0.05 \mathrm{mM})$ intervention group

Figure 3 Resveratrol treatment inhibits LPS-induced monocyte migration and inflammation. (A) Detection of IL-6 expression in cells; (B) detection of TNF $\alpha$ expression in cells; (C) detection of IL-1 expression in cells; (D) detection of MCP-1 expression in cells; (E) transwell detects changes in cell migration ability; (F) qRT-PCR detection of cell HMGB1 expression; (G) qRT-PCR detection of cell NF-кB expression; (H) resveratrol inhibited LPS-induced activation of NF-kB-p65. Each bar represents the mean \pm SD for triplicate measurements. ${ }^{* *}, \mathrm{P}<0.01$. 
A

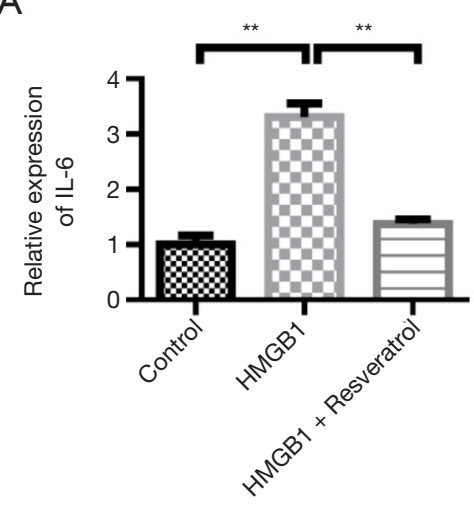

$\mathrm{D}$

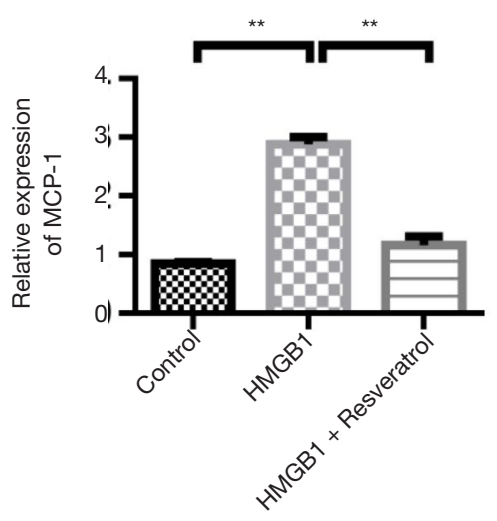

B

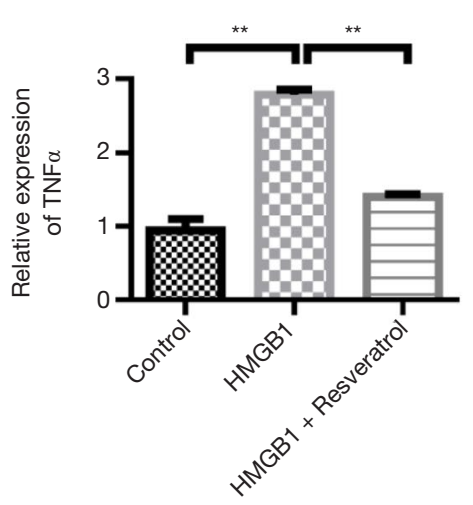

$\mathrm{E}$

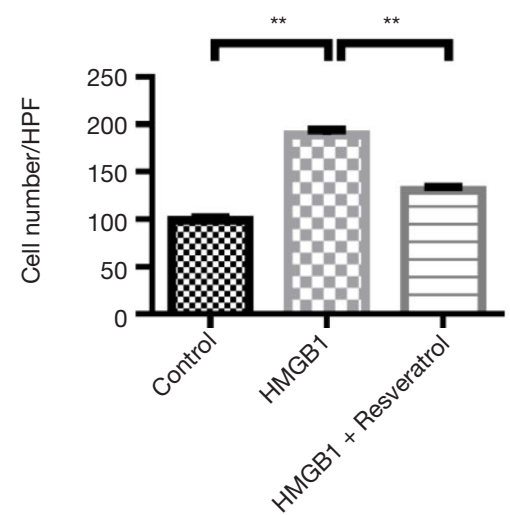

C

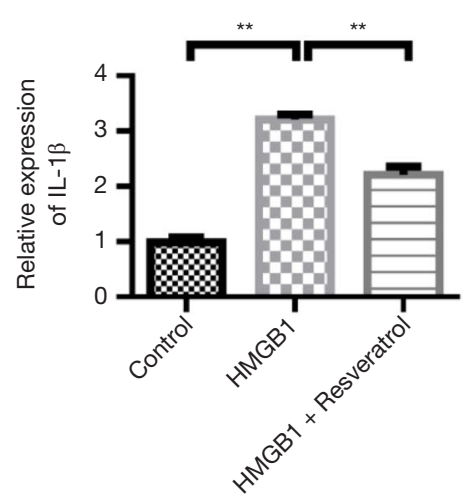

$\mathrm{F}$

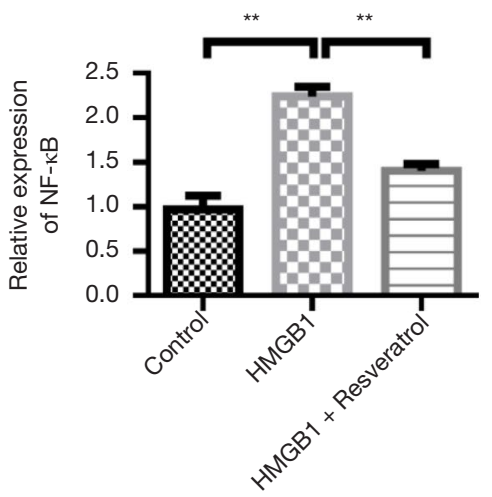

Figure 4 Resveratrol treatment inhibits the migration and inflammation of monocytes induced by HMGB1. (A) Detection of IL-6 expression in cells; (B) detection of TNF $\alpha$ expression in cells; (C) detection of IL-1 $\beta$ expression in cells; (D) detection of MCP-1 expression in cells; (E) transwell detects changes in cell migration ability; (F) qRT-PCR detection of cell NF-кB expression. Each bar represents the mean \pm SD for triplicate measurements. ${ }^{* *}, \mathrm{P}<0.01$.

showed that the cell proliferation rate was highest in the control group. STS significantly inhibited cell proliferation. LPS stimulation promoted THP-1 cell proliferation. However, Resveratrol treatment inhibited THP-1 cell proliferation rate (Figure 5 E).

\section{Resveratrol treatment increases apoptosis and inhibit proliferation in HMGB1 induced monocytes}

THP-1 cells were stimulated by STS and HMGB1. The experimental results showed that STS induced apoptosis. However, Resveratrol treatment could improve the apoptosis rate (Figure 6A). QRT-PCR results showed that compared with the control group, apoptosis-related proteins Bax and Cyt-C were significantly increased in the STS treatment group. However, HMGB1 treatment reduced the expressions of Bax and Cyt-C. Resveratrol upregulated the expressions of Bax and Cyt-C (Figure 6B,6C). The variation trend of Bcl-2 expression was contrary to that of Bax (Figure 6D). The cell proliferation experiment results showed that the cell proliferation rate was higher in the control group. HMGB1 stimulation can promote THP-1 cell proliferation. However, Resveratrol treatment inhibited THP-1 cell proliferation rate (Figure 6E).

\section{Discussion}

The anti-inflammatory role of Resveratrol is a central mechanism underlying its multiple therapeutic effects (19). Resveratrol could regulate the inflammation process induced by various stimuli and in different experimental models (20). Resveratrol could relieve the 
A

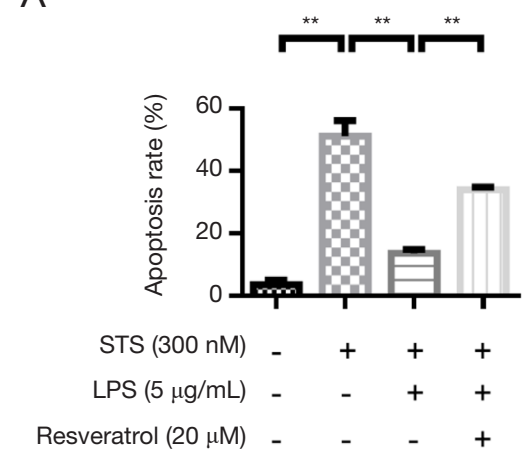

C
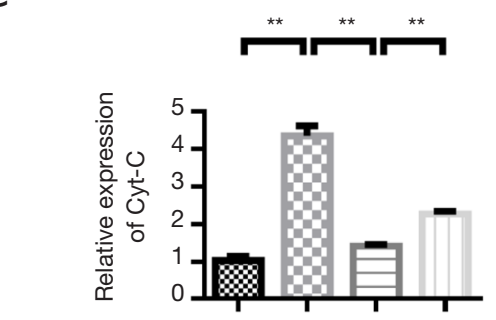

STS $(300 \mathrm{nM})$ - $+\quad+$

$\operatorname{LPS}(5 \mu \mathrm{g} / \mathrm{mL})$ - $\quad+\quad+$

Resveratrol $(20 \mu \mathrm{M})$ - $\quad$ - $\quad$ - $\quad+$

$\mathrm{E}$
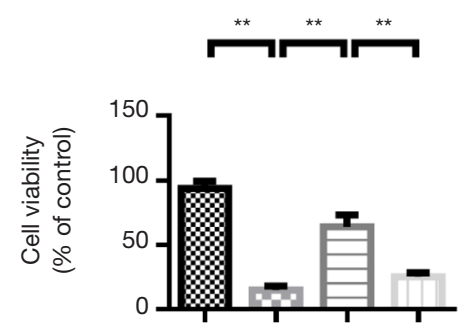

STS $(300 \mathrm{nM}) \quad-\quad+\quad+\quad+$

$\operatorname{LPS}(5 \mu \mathrm{g} / \mathrm{mL}) \quad-\quad-\quad+\quad+$

Resveratrol $(20 \mu \mathrm{M}) \quad$ - $\quad$ - $\quad$ - $\quad+$
B

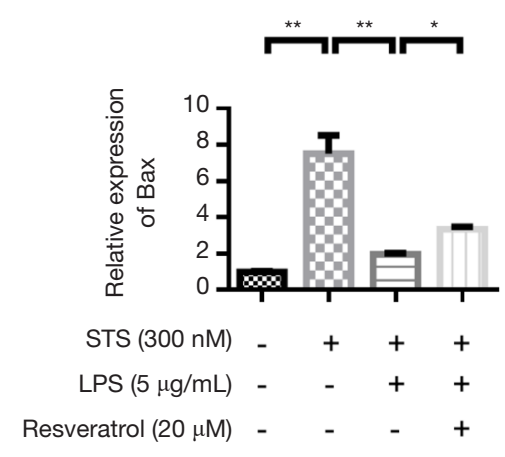

D

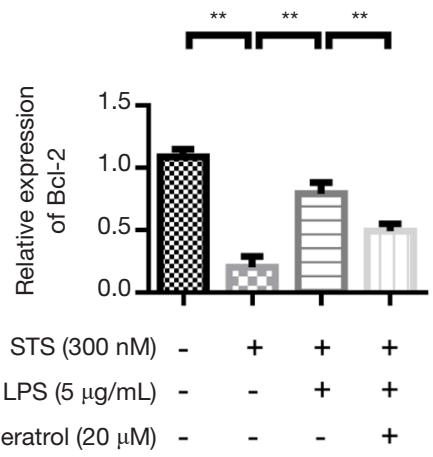

Figure 5 Resveratrol treatment increases monocyte apoptosis and reverses the anti-apoptotic effect induced by LPS. (A) Detection of apoptosis rate; (B) qRT-PCR detection of Bax expression in cells; (C) qRT-PCR to detect cell Cyt-C expression; (D) qRT-PCR to detect cell Bcl-2 expression; (E) CCK-8 detects cell proliferation rate. Each bar represents the mean \pm SD for triplicate measurements. ${ }^{*}, \mathrm{P}<0.05$; ${ }^{* *}$, $\mathrm{P}<0.01$.

inflammatory process by reducing the cytokines, such as CRP, TNFa, IL-6, and MCP-1 (21-23).

HMGB1 is an intracellular DNA-binding protein located in undifferentiated tissues, such as hepatocytes and neurons $(24,25)$. It was first discovered in an endotoxemia animal model and later confirmed to be released as a cytokine by activated monocyte/macrophage or necrotic cells in pathological conditions (26,27). Different from early response cytokines, such as TNF $\alpha$ and IL-6, HMGB1 is secreted after a $12-16 \mathrm{~h}$ delay. To be released, it is first translocated from the nucleus to the secretory lysosome in cytoplasm. Phosphorylation and acetylation are required in this process. In our study, we observed the increased HMGB1 level and the translocation of HMGB1 from 
A

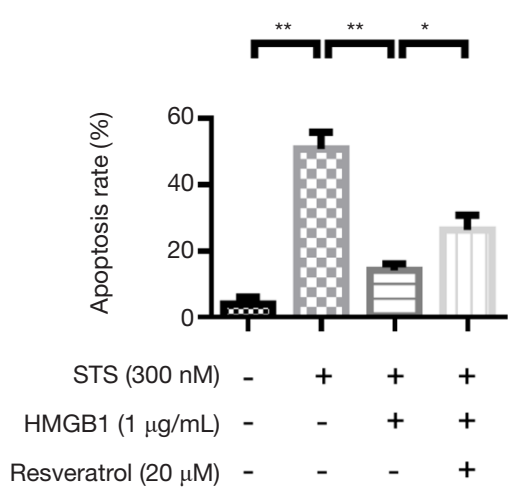

C

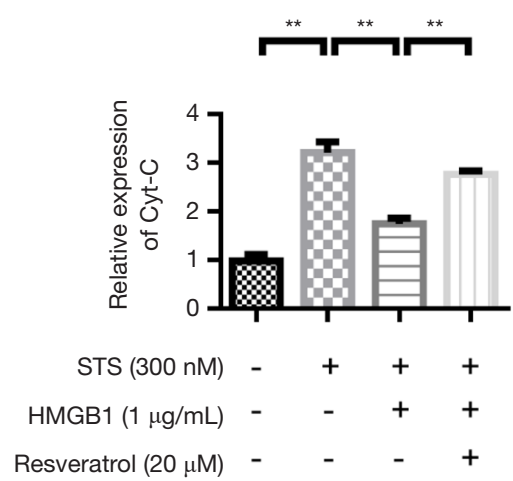

$\mathrm{E}$
B

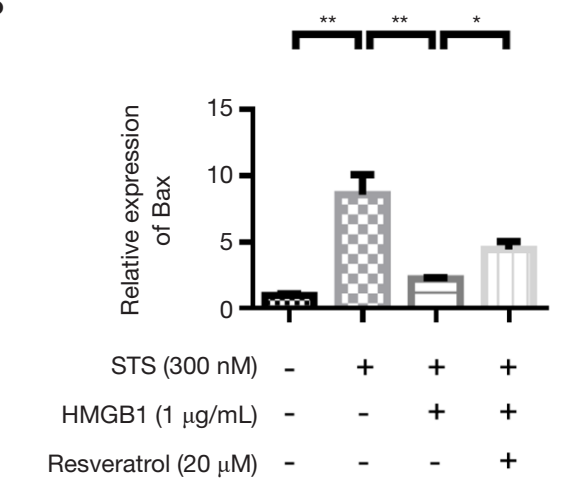

D

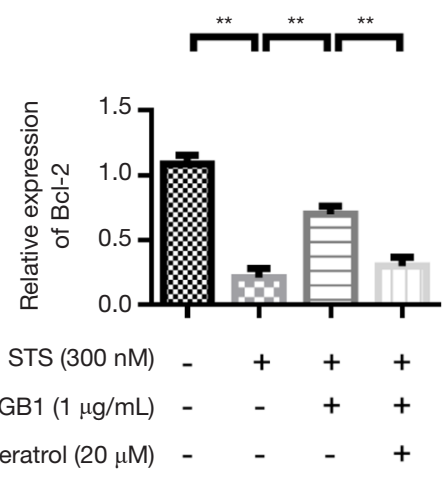

Figure 6 Resveratrol treatment increases monocyte apoptosis and reverses the anti-apoptotic effect induced by HMGB1. (A) Detection of apoptosis rate; (B) qRT-PCR detection of Bax expression in cells; (C) qRT-PCR to detect cell Cyt-C expression; (D) qRT-PCR to detect cell Bcl-2 expression; (E) CCK-8 detects cell proliferation rate. Each bar represents the mean \pm SD for triplicate measurements. *, $\mathrm{P}<0.05 ;{ }^{* *}$, $\mathrm{P}<0.01$.

nucleus to cytoplasm. This finding indicated that LPS successfully activated HMGB1 and increased its secretion, which were both inhibited by resveratrol. The mechanisms contributing to the effect of Resveratrol on HMGB1 may be complex.

LPS is a typical endotoxin that elicits an immune response $(28,29)$. NF- $\mathrm{\kappa B}$ is the major regulating factor in LPS-stimulated response. Most studies reported that NF$\kappa \mathrm{B}$ activation is essential for HMGB1 translocation (29). Oh et al. reported the release of HMGB1 in a NF- $\mathrm{KB}-$ independent manner, but SN50 and BAY-11-7082 were used as the NF- $\mathrm{KB}$ inhibitors, which functioned under a 
mechanism different from that of PDTC (30). HMGB1 release might be $\mathrm{NF}-\kappa \mathrm{B}$-dependent, because it could be blocked by an NF- $\kappa \mathrm{B}$ inhibitor. The inhibitory effect of Resveratrol on NF- $\kappa \mathrm{B}$ has been confirmed in the past $(31,32)$. Resveratrol may inhibit NF- $\kappa \mathrm{B}$ activation by either blocking p65 phosphorylation or IкB kinase activity (33). In our study, Resveratrol decreased NF- $\mathrm{\kappa B}-\mathrm{p} 65$ expression at the protein level. The activity of NF-кB-p65 was inhibited by resveratrol. So, we concluded that the decrease of HMGB1 by resveratrol was partially achieved by interfering with the NF-kB-p65 signal.

After release, HMGB1 interacts with its ligands, namely, Toll-like-receptor 2 (TLR), TLR4, and advanced glycation end products (RAGE), to elicit inflammation. The binding of HMGB1 with its membranous receptors activates intracellular signal pathway involving NF-кB. HMGB1 stimulates human monocyte to synthesize proinflammatory cytokines (34). HMGB1 can bind to LPS to synergize the inflammation response (35). The combination of released HMGB1 with its ligand, such as TLR4, can subsequently activate NF- $\kappa \mathrm{B}$ and the downstream cytokines. Thus, a circuit of HMGB1-receptor-NF- $\kappa \mathrm{B}$ was formed and inflammatory response was amplified. With the possibility of repressing both TLR and NF- $\kappa \mathrm{B}$, Resveratrol may cut off the circuit to reduce the level of HMGB1.

Monocyte migration is an essential process in inflammation response $(36,37)$. Ferrero et al. reported that Resveratrol inhibited the adhesion of U937 monocyte to LPS-stimulated endothelial cells in vitro (38). Our data demonstrated that THP-1 migration in response to LPS stimulation was inhibited by resveratrol. HMGB1 secreted by monocyte could directly mediate monocyte migration and cell-to-cell interaction. Released MCP-1 may act in concert with HMGB1 to elicit the monocyte migration. Thus, the inhibitory effect of Resveratrol on THP-1 migration may result from decrease of HMGB1 and MCP1 or from the inhibition on NF- $\kappa B$ signaling.

The effect of resveratrol was only evaluated in vitro. However, resveratrol has shown remarkable efficacy for cancer treatment in vivo (39). Moreover, resveratrol acts as a chemopreventive agent in the four major stages of carcinogenesis, namely, initiation, promotion, progression, and metastasis (40). However, Resveratrol is not easily soluble. A study in healthy volunteers showed that a serum concentration of $4.24 \mu \mathrm{M}$ was obtained for resveratrol after repeated doses at $5 \mathrm{~g}$ (41). However, Resveratrol can bind extensively (97.6\%) and tightly to human serum albumin with an affinity association constant of $\mathrm{K}=2.56 \times 105$
M-1 (42), which greatly facilitates its accessibility to body tissues, including tumor tissues, leading to a large volume of distribution (41). Resveratrol might have a remarkable effect on monocytes in vivo.

\section{Conclusions}

A novel anti-inflammatory mechanism for Resveratrol was suggested. Resveratrol inhibited the translocation and release of HMGB1 in LPS-stimulated THP-1 cells. Monocyte migration induced by LPS was blocked by resveratrol. NF- $\mathrm{KB}$ signaling was possibly involved in the effect of Resveratrol on HMGB1 and monocyte migration. Therefore, the inhibitory effect of Resveratrol on LPS and HMGB1 on monocyte migration and apoptosis may be realized through the NF- $\mathrm{\kappa B} / \mathrm{MCP}-1$ pathway. Resveratrol restores the normal function of monocytes, thereby leading to a reduction in systemic inflammation.

\section{Acknowledgments}

Funding: This work is supported by the Natural Science Foundation of Hunan Province (Grant Number 2020JJ5846).

\section{Footnote}

Reporting Checklist: The authors have completed the MDAR reporting checklist. Available at https://dx.doi. org/10.21037/tcr-21-517

Data Sharing Statement: Available at https://dx.doi. org/10.21037/tcr-21-517

Conflicts of Interest: All authors have completed the ICMJE uniform disclosure form (available at https://dx.doi. org/10.21037/tcr-21-517). The authors have no conflicts of interest to declare.

Ethical Statement: The authors are accountable for all aspects of the work in ensuring that questions related to the accuracy or integrity of any part of the work are appropriately investigated and resolved. The study was conducted in accordance with the Declaration of Helsinki (as revised in 2013). Institutional ethical approval was waived.

Open Access Statement: This is an Open Access article distributed in accordance with the Creative Commons 
Attribution-NonCommercial-NoDerivs 4.0 International License (CC BY-NC-ND 4.0), which permits the noncommercial replication and distribution of the article with the strict proviso that no changes or edits are made and the original work is properly cited (including links to both the formal publication through the relevant DOI and the license). See: https://creativecommons.org/licenses/by-nc-nd/4.0/.

\section{References}

1. Xu H, Chen M, Forrester JV. Para-inflammation in the aging retina. Prog Retin Eye Res 2009;28:348-68.

2. Chung HY, Sung B, Jung KJ, et al. The molecular inflammatory process in aging. Antioxid Redox Signal 2006;8:572-81.

3. Jose SS, Bendickova K, Kepak T, et al. Chronic Inflammation in Immune Aging: Role of Pattern Recognition Receptor Crosstalk with the Telomere Complex? Front Immunol 2017;8:1078.

4. van der Valk FM, Bekkering S, Kroon J, et al. Oxidized Phospholipids on Lipoprotein(a) Elicit Arterial Wall Inflammation and an Inflammatory Monocyte Response in Humans. Circulation 2016;134:611-24.

5. Chimen M, Yates CM, McGettrick HM, et al. Monocyte Subsets Coregulate Inflammatory Responses by Integrated Signaling through TNF and IL-6 at the Endothelial Cell Interface. J Immunol 2017;198:2834-43.

6. Niu M, Jiang Z, Xin X, et al. Effect of HMGB1 on monocyte immune function in respiratory syncytial virus bronchiolitis. Exp Ther Med 2021;21:75.

7. Son M, Porat A, He M, et al. C1q and HMGB1 reciprocally regulate human macrophage polarization. Blood 2016;128:2218-28.

8. Liu T, Xiang A, Peng T, et al. HMGB1-C1q complexes regulate macrophage function by switching between leukotriene and specialized proresolving mediator biosynthesis. Proc Natl Acad Sci U S A 2019;116:23254-63.

9. Moussa C, Hebron M, Huang X, et al. Resveratrol regulates neuro-inflammation and induces adaptive immunity in Alzheimer's disease. J Neuroinflammation 2017;14:1.

10. Tian Y, Ma J, Wang W, et al. Resveratrol supplement inhibited the NF- $\mathrm{KB}$ inflammation pathway through activating AMPK $\alpha$-SIRT1 pathway in mice with fatty liver. Mol Cell Biochem 2016;422:75-84.

11. Chiang MC, Nicol CJ, Cheng YC. Resveratrol activation of AMPK-dependent pathways is neuroprotective in human neural stem cells against amyloid-beta-induced inflammation and oxidative stress. Neurochem Int 2018;115:1-10.

12. Ko JH, Sethi G, Um JY, et al. The Role of Resveratrol in Cancer Therapy. Int J Mol Sci 2017;18:2589.

13. Rauf A, Imran M, Butt MS, et al. Resveratrol as an anti-cancer agent: A review. Crit Rev Food Sci Nutr 2018;58:1428-47.

14. Kim EN, Kim MY, Lim JH, et al. The protective effect of resveratrol on vascular aging by modulation of the reninangiotensin system. Atherosclerosis 2018;270:123-31.

15. Samsamikor M, Daryani NE, Asl PR, et al. Resveratrol Supplementation and Oxidative/Anti-Oxidative Status in Patients with Ulcerative Colitis: A Randomized, DoubleBlind, Placebo-controlled Pilot Study. Arch Med Res 2016;47:304-9.

16. Cosín-Tomàs M, Senserrich J, Arumí-Planas M, et al. Role of Resveratrol and Selenium on Oxidative Stress and Expression of Antioxidant and Anti-Aging Genes in Immortalized Lymphocytes from Alzheimer's Disease Patients. Nutrients 2019;11:1764.

17. de Sá Coutinho D, Pacheco MT, Frozza RL, et al. AntiInflammatory Effects of Resveratrol: Mechanistic Insights. Int J Mol Sci 2018;19:1812.

18. Dull AM, Moga MA, Dimienescu OG, et al. Therapeutic Approaches of Resveratrol on Endometriosis via AntiInflammatory and Anti-Angiogenic Pathways. Molecules 2019;24:667.

19. Thiel G, Ulrich M, Mukaida N, et al. Resveratrol stimulation induces interleukin-8 gene transcription via NF- B. Pharmacol Res 2018;134:238-45.

20. Palomera-Ávalos V, Griñán-Ferré C, Izquierdo V, et al. Resveratrol modulates response against acute inflammatory stimuli in aged mouse brain. Exp Gerontol 2018;102:3-11.

21. Koushki M, Dashatan NA, Meshkani R. Effect of Resveratrol Supplementation on Inflammatory Markers: A Systematic Review and Meta-analysis of Randomized Controlled Trials. Clin Ther 2018;40:1180-92.e5.

22. Sadeghi A, Seyyed Ebrahimi SS, Golestani A, et al. Resveratrol Ameliorates Palmitate-Induced Inflammation in Skeletal Muscle Cells by Attenuating Oxidative Stress and JNK/NF- $\kappa B$ Pathway in a SIRT1-Independent Mechanism. J Cell Biochem 2017;118:2654-63.

23. Yazir Y, Demirtaş Şahin T, Furat Rençber S, et al. Restorative effect of resveratrol on expression of endothelial and neuronal nitric oxide synthase in cavernous tissues of chronic unpredictable mild stressexposed rats: an impact of inflammation. Int J Impot Res 
2018;30:318-26.

24. Wang B, Huang X, Pan X, et al. Minocycline prevents the depressive-like behavior through inhibiting the release of HMGB1 from microglia and neurons. Brain Behav Immun 2020;88:132-43.

25. Paudel YN, Angelopoulou E, C BK, et al. High mobility group box 1 (HMGB1) protein in Multiple Sclerosis (MS): Mechanisms and therapeutic potential. Life Sci 2019;238:116924.

26. Peng HH, Liu YJ, Ojcius DM, et al. Mineral particles stimulate innate immunity through neutrophil extracellular traps containing HMGB1. Sci Rep 2017;7:16628.

27. Sekiguchi F, Domoto R, Nakashima K, et al. Paclitaxelinduced HMGB1 release from macrophages and its implication for peripheral neuropathy in mice: Evidence for a neuroimmune crosstalk. Neuropharmacology 2018;141:201-13.

28. Zeng XY, Yuan W, Zhou L, et al. Forsythoside A exerts an anti-endotoxin effect by blocking the LPS/TLR4 signaling pathway and inhibiting Tregs in vitro. Int J Mol Med 2017;40:243-50.

29. Khan HN, Perlee D, Schoenmaker L, et al. Leukocyte transcriptional signatures dependent on LPS dosage in human endotoxemia. J Leukoc Biol 2019;106:1153-60.

30. Oh YJ, Youn JH, Ji Y, et al. HMGB1 is phosphorylated by classical protein kinase $\mathrm{C}$ and is secreted by a calciumdependent mechanism. J Immunol 2009;182:5800-9.

31. Ren Z, Wang L, Cui J, et al. Resveratrol inhibits NF-kB signaling through suppression of p65 and IkappaB kinase activities. Pharmazie 2013;68:689-94.

32. Manna SK, Mukhopadhyay A, Aggarwal BB. Resveratrol suppresses TNF-induced activation of nuclear transcription factors NF-kappa B, activator protein-1, and apoptosis: potential role of reactive oxygen intermediates

Cite this article as: Zhang Y, Dong Q, Liu C, Zhu Y, Qin X, Qi Z, Zhang X, Guo H, Li W, Liu M, Gan L, Liu H. Resveratrol affects the migration and apoptosis of monocytes by blocking HMGB1/NF- $\kappa$ B pathway. Transl Cancer Res 2021;10(8):3647-3658. doi: 10.21037/tcr-21-517 and lipid peroxidation. J Immunol 2000;164:6509-19.

33. Kumar A, Sharma SS. NF-kappaB inhibitory action of resveratrol: a probable mechanism of neuroprotection in experimental diabetic neuropathy. Biochem Biophys Res Commun 2010;394:360-5.

34. Wang H, Yang H, Czura CJ, et al. HMGB1 as a late mediator of lethal systemic inflammation. Am J Respir Crit Care Med 2001;164:1768-73.

35. Chen G, Ward MF, Sama AE, et al. Extracellular HMGB1 as a proinflammatory cytokine. J Interferon Cytokine Res 2004;24:329-33.

36. Shi C, Pamer EG. Monocyte recruitment during infection and inflammation. Nat Rev Immunol 2011;11:762-74.

37. Wrigley BJ, Lip GY, Shantsila E. The role of monocytes and inflammation in the pathophysiology of heart failure. Eur J Heart Fail 2011;13:1161-71.

38. Ferrero ME, Bertelli AE, Fulgenzi A, et al. Activity in vitro of resveratrol on granulocyte and monocyte adhesion to endothelium. Am J Clin Nutr 1998;68:1208-14.

39. Ren B, Kwah MX, Liu C, et al. Resveratrol for cancer therapy: Challenges and future perspectives. Cancer Lett 2021;515:63-72.

40. Jang M, Cai L, Udeani GO, et al. Cancer chemopreventive activity of resveratrol, a natural product derived from grapes. Science 1997;275:218-20.

41. Brown VA, Patel KR, Viskaduraki M, et al. Repeat dose study of the cancer chemopreventive agent resveratrol in healthy volunteers: safety, pharmacokinetics, and effect on the insulin-like growth factor axis. Cancer Res 2010;70:9003-11.

42. N' soukpoe-Kossi CN, St-Louis C, Beauregard M, et al. Resveratrol binding to human serum albumin. J Biomol Struct Dyn 2006;24:277-83. 